\title{
Magnetization Reversal Processes in Nanocrystalline (Pr, Dy)-(Fe, Co)-B Bulk Alloys
}

\author{
A. Przybye*, K. Pawlik, P. Pawlik, P. GęBara, J.J. WysŁocki
}

Institute of Physics, Częstochowa University of Technology, al. Armii Krajowej 19, 42-200 Częstochowa, Poland

The aim of this paper was to study the phase constitution, magnetic properties and magnetization reversal processes in the rapidly solidified bulk (Pr,Dy)-(Fe,Co)-B alloys doped with $\mathrm{Zr}$, Ti, Mn and Ni. The $3 \mathrm{~mm}$ outer diameter tubes samples of the $\left.\operatorname{Pr}_{8} \mathrm{Dy}_{1} \mathrm{Fe}_{60} \mathrm{Co}_{7} \mathrm{Ni}_{(6}{ }_{x}\right) \mathrm{Mn}_{x} \mathrm{~B}_{14} \mathrm{Zr}_{1} \mathrm{Ti}_{3}$ (where $x=0,3$,6) alloys were produced by suction-casting technique. The admixture of $\mathrm{Zr}$ was introduced in order to improve their glass forming abilities while Dy was substituted to enhance the magnetocrystalline anisotropy of hard magnetic phase. The effect of Ni and $\mathrm{Mn}$ addition on the phase constitution and magnetic properties was studied in the presented work.

DOI: $10.12693 /$ APhysPolA.127.579

PACS: 75.20.En, 75.75.-c, 75.75.Cd

\section{Introduction}

From the technological point of view, the amorphous and nanocrystalline Fe-based alloys are very important materials, due to their good magnetic properties and low cost [1-3]. In order to extend their commercial use, bulk components of amorphous or nanocrystalline microstructure are produced by several techniques. Relatively new procedures of obtaining bulk magnetic materials are the rapid quenching techniques - suction or injection casting methods $[4,5]$. Interesting results concerning processing bulk metallic glasses were obtained for $\mathrm{Fe}-\mathrm{Co}-$ $\mathrm{Zr}-\mathrm{W}-\mathrm{B}$ alloys in the form of tubes with outer diameter $3 \mathrm{~mm}$ and rods with maximum diameter up to $2 \mathrm{~mm} \mathrm{[6-}$ 8]. It was revealed that depending on the sample diameter and shape, various cooling rates can be obtained in the suction casting process [9]. This technique was also used for manufacturing nanocrystalline RE-Fe-Btype $(\mathrm{RE}=\mathrm{Nd}, \mathrm{Pr}, \mathrm{Dy})$ permanent magnets, where short processing time and better corrosion resistance than for magnets prepared by conventional methods seems to be advantageous. This type of products can find application as miniature ring-type magnets or stepper motors dedicated for example to electronic watches [10]. The effect of $\mathrm{Ni}$ and $\mathrm{Mn}$ addition on phase constitution and magnetic properties ( $\mathrm{Pr}, \mathrm{Dy})-(\mathrm{Fe}, \mathrm{Co})-\mathrm{B}-\mathrm{Zr}-\mathrm{Ti}$ alloys in form of ribbons was described in our previous studies in [11]. In present paper the phase constitution and magnetic properties of $\mathrm{Pr}_{8} \mathrm{Dy}_{1} \mathrm{Fe}_{60} \mathrm{Co}_{7} \mathrm{Ni}_{(6-x)} \mathrm{Mn}_{x} \mathrm{~B}_{14} \mathrm{Zr}_{1} \mathrm{Ti}_{3}$ (where $x=0,3,6$ ) in the form of $3 \mathrm{~mm}$ outer diameter tubes alloys were discussed. Furthermore, for samples containing $\mathrm{Mn}$, magnetization reversal processes were investigated.

\section{Samples preparations and experimental methods}

Alloy ingots with nominal compositions of the $\mathrm{Pr}_{8} \mathrm{Dy}_{1} \mathrm{Fe}_{60} \mathrm{Co}_{7} \mathrm{Ni}_{(6-x)} \mathrm{Mn}_{x} \mathrm{~B}_{14} \mathrm{Zr}_{1} \mathrm{Ti}_{3}$ (where $x=0,3,6$ )

\footnotetext{
* corresponding author; e-mail: przybyl@wip.pcz.pl
}

were prepared by arc-melting under an argon atmosphere using high purity constituent elements with pre-alloyed $\mathrm{Fe}-\mathrm{B}$ of known composition. Then the samples were homogenized by systematic re-melting. Subsequently, samples in the form of $3 \mathrm{~mm}$ outer diameter thin walls tubes were prepared by the suction-casting technique. The phase structure of the as-cast samples was investigated by X-ray diffractometry (XRD) with $\mathrm{Cu} K_{\alpha}$ radiation $(\lambda=1.54 \mathrm{~nm})$. The room temperature major and minor hysteresis loops, as well as sets of recoil curves were performed using a vibrating sample magnetometer (LakeShore VSM) in the external magnetic field up to $1600 \mathrm{kA} / \mathrm{m}$, on specimens prepared from tubes. The minor hysteresis loops were used to obtain the field dependences of remanence $J_{\mathrm{r}}$ and coercivity ${ }_{J} H_{\mathrm{c}}$. The series of recoil curves were obtained for the initially saturated samples and for the thermally demagnetized specimens.

\section{Results}

X-ray diffraction patterns collected for $\mathrm{Pr}_{8} \mathrm{Dy}_{1} \mathrm{Fe}_{60} \mathrm{Co}_{7} \mathrm{Ni}_{(6-x)} \mathrm{Mn}_{x} \mathrm{~B}_{14} \mathrm{Zr}_{1} \mathrm{Ti}_{3}$ (where $x=0$, 3,6 ) alloys are presented in Fig. 1. All investigated samples are crystalline in the as-cast state. For samples containing 6 at.\% of $\mathrm{Ni}$ coexistence of two phases: dominant soft magnetic $\alpha-(\mathrm{Fe}, \mathrm{Ni})$ phase and a small amount of hard magnetic $\operatorname{Pr}_{2}(\mathrm{Fe}, \mathrm{Co})_{14} \mathrm{~B}$ phase, were shown (Fig. 1a). As it was shown (Fig. 1b and c), the increase of $\mathrm{Mn}$ admixture in alloy composition leads to the increase of volume fraction of the hard magnetic $\operatorname{Pr}_{2}(\mathrm{Fe}, \mathrm{Co})_{14} \mathrm{~B}$ phase thus leading to the improvement of the magnetic properties. Furthermore for the Mn containing samples no evidences of presence of the soft magnetic phase was shown. The peaks corresponding to recognized phases are marked in Fig. 1.

It is supposed that $\mathrm{Mn}$ and $\mathrm{Ni}$ atoms together with $\mathrm{Zr}$ and $\mathrm{Ti}$ additions were located in the disordered soft magnetic phase and/or precipitated at the boundaries crystalline phases. The Rietveld analysis carried out for sample with 6 at.\% of $\mathrm{Ni}$, showed larger lattice constant $a$ of soft magnetic phase $\alpha-(\mathrm{Fe}, \mathrm{Ni})$ than that for a pure $\alpha$-Fe, which suggests that the $\mathrm{Ni}$ atoms occupies Fe positions in the unit cell of bcc $\alpha$-Fe phase. It was also shown 


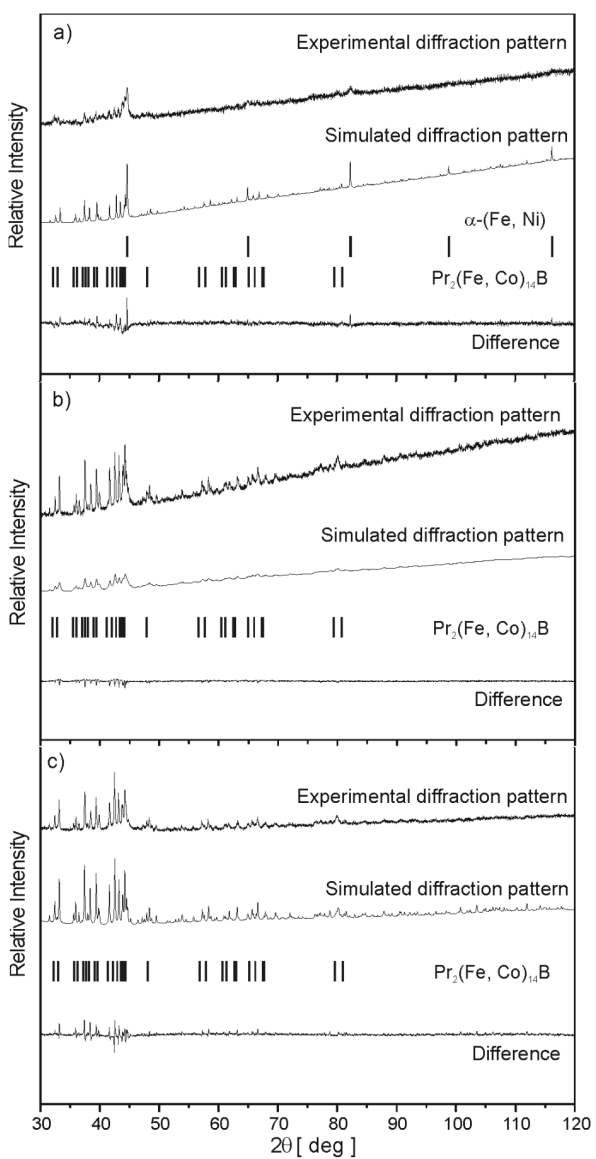

Fig. 1. The experimental X-ray diffraction data together with the Rietveld analysis and differences between experiment and calculations for the as-cast $\mathrm{Pr}_{8} \mathrm{Dy}_{1} \mathrm{Fe}_{60} \mathrm{Co}_{7} \mathrm{Ni}_{6} \mathrm{~B}_{14} \mathrm{Zr}_{1} \mathrm{Ti}_{3} \quad$ (a) $\mathrm{Pr}_{8} \mathrm{Dy}_{1} \mathrm{Fe}_{60} \mathrm{Co}_{7} \mathrm{Ni}_{3} \mathrm{Mn}_{3} \mathrm{~B}_{14} \mathrm{Zr}_{1} \mathrm{Ti}_{3} \quad$ (b) and $\mathrm{Pr}_{8} \mathrm{Dy}_{1} \mathrm{Fe}_{60} \mathrm{Co}_{7} \mathrm{Mn}_{6} \mathrm{~B}_{14} \mathrm{Zr}_{1} \mathrm{Ti}_{3}$ (c) alloys in the form of thin walls $3 \mathrm{~mm}$ outer diameter tubes.

that with the increase of Mn contents, a slight decrease of lattice constants of hard magnetic phase occurs. Such phenomenon can be related to replacement of Fe atoms by $\mathrm{Mn}$ in the unit cell of the in hard magnetic phase. Results of the Rietveld analysis were collected in Table I.

TABLE I

Lattice constants of recognized magnetic phases for all investigated alloys.

\begin{tabular}{c|c|c|c}
\hline \hline \multirow{2}{*}{ Sample } & $\alpha$-(Fe,Ni) & \multicolumn{2}{|c}{$\mathrm{Pr}_{2}(\mathrm{Fe}, \mathrm{Co})_{14} \mathrm{~B}$} \\
\cline { 2 - 4 } & $a[\mathrm{~nm}]$ & $a[\mathrm{~nm}]$ & $c[\mathrm{~nm}]$ \\
\hline $\mathrm{Pr}_{8} \mathrm{Dy}_{1} \mathrm{Fe}_{60} \mathrm{Co}_{7} \mathrm{Ni}_{6} \mathrm{~B}_{14} \mathrm{Zr}_{1} \mathrm{Ti}_{3}$ & 0.287 & 0.8801 & 1.2251 \\
$\mathrm{Pr}_{8} \mathrm{Dy}_{1} \mathrm{Fe}_{60} \mathrm{Co}_{7} \mathrm{Ni}_{3} \mathrm{Mnn}_{3} \mathrm{~B}_{14} \mathrm{Zr}_{1} \mathrm{Ti}_{3}$ & - & 0.8779 & 1.2179 \\
$\mathrm{Pr}_{8} \mathrm{Dy}_{1} \mathrm{Fe}_{60} \mathrm{Co}_{7} \mathrm{Mn}_{6} \mathrm{~B}_{14} \mathrm{Zr}_{1} \mathrm{Ti}_{3}$ & - & 0.8776 & 1.2167
\end{tabular}

Major hysteresis loops and initial magnetization curves measured in external magnetic field up to $1600 \mathrm{kA} / \mathrm{m}$ were shown in Fig. 2, respectively. Initial magnetization curves were used to determine saturation polarization $\mathrm{J}_{\mathrm{s}}$ for all investigated samples. The magnetic parameters of the investigated specimens were collected in Table II.

It was shown that the highest saturation polarization had the sample doped with 6 at.\% of Ni. However, the

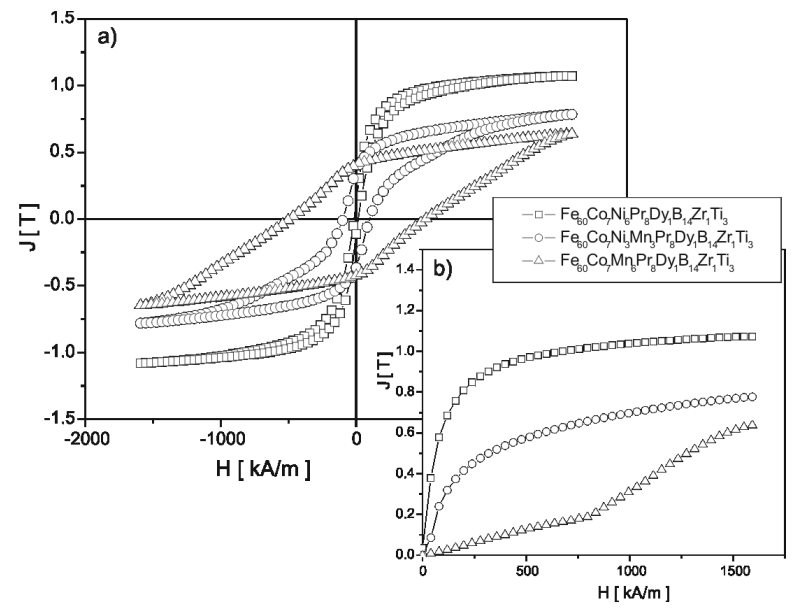

Fig. 2. The hysteresis loops (a) and initial magnetization curves (b) measured for $\mathrm{Pr}_{8} \mathrm{Dy}_{1} \mathrm{Fe}_{60} \mathrm{Co}_{7} \mathrm{Ni}_{(6-x)} \mathrm{Mn}_{x} \mathrm{~B}_{14} \mathrm{Zr}_{1} \mathrm{Ti}_{3}$ (where $x=0$, $3,6)$ alloys tubes.

TABLE II

Magnetic properties of $\operatorname{Pr}_{8} \mathrm{Dy}_{1} \mathrm{Fe}_{60} \mathrm{Co}_{7} \mathrm{Ni}_{(6-x)} \mathrm{Mn}_{x} \mathrm{~B}_{14} \mathrm{Zr}_{1} \mathrm{Ti}_{3}$ (where $x=0,3,6$ ) alloys in the form of $3 \mathrm{~mm}$ outer diameter tubes.

\begin{tabular}{l|c|c|c|c|c}
\hline \hline \multirow{2}{*}{$\begin{array}{c}\text { Samples } \\
\text { tube } 3 \mathrm{~mm} \text { as-cast }\end{array}$} & $J_{\mathrm{c}} H_{\mathrm{c}}$ & $\mathrm{J}_{\mathrm{r}}$ & $\mathrm{J}_{\mathrm{s}}$ & $\mathrm{J}_{\mathrm{r}} / \mathrm{J}_{\mathrm{s}}$ & $(B H)_{\max }$ \\
\cline { 2 - 6 } & {$\left[\frac{\mathrm{kA}}{\mathrm{m}}\right]$} & {$[\mathrm{T}]$} & {$[\mathrm{T}]$} & {$[-]$} & {$\left[\frac{\mathrm{kJ}}{\mathrm{m}^{3}}\right]$} \\
\hline $\mathrm{Pr}_{8} \mathrm{Dy}_{1} \mathrm{Fe}_{60} \mathrm{Co}_{7} \mathrm{Ni}_{6} \mathrm{~B}_{14} \mathrm{Zr}_{1} \mathrm{Ti}_{3}$ & 15 & 0.121 & 1.08 & 0.11 & 0.399 \\
$\mathrm{Pr}_{8} \mathrm{Dy}_{1} \mathrm{Fe}_{60} \mathrm{Co}_{7} \mathrm{Ni}_{3} \mathrm{Mn}_{3} \mathrm{~B}_{14} \mathrm{Zr}_{1} \mathrm{Ti}_{3}$ & 100 & 0.365 & 0.79 & 0.46 & 5.572 \\
$\mathrm{Pr}_{8} \mathrm{Dy}_{1} \mathrm{Fe}_{60} \mathrm{Co}_{7} \mathrm{Mn}_{6} \mathrm{~B}_{14} \mathrm{Zr}_{1} \mathrm{Ti}_{3}$ & 502 & 0.433 & 0.67 & 0.65 & 22.5
\end{tabular}

coercivity field ${ }_{J} H_{\mathrm{C}}$ measured for this alloy is relatively low just like for a semi-hard ferromagnetic. Magnetic properties were improved by the change of chemical composition of the alloy, which was made by addition of Mn atoms. With an increase of Mn admixture, an increase of remanence $J_{\mathrm{r}}$ and coercivity field ${ }_{J} H_{\mathrm{C}}$ was observed, while decrease of saturation polarization was noticed. The best magnetic properties were measured for sample containing 6 at.\% Mn. Changes in the shape of magnetic hysteresis loops reflect changes in the phase constitution of investigated samples.

Even though the maximum magnetic field is relatively low, the obtained values of ${ }_{J} H_{\mathrm{C}}$ and $J_{\mathrm{s}}$ are close to maximum due to low volume fraction of the hard magnetic phase in the samples volume. Furthermore, interesting changes in the shapes of recoil curves that give insight into the magnetization reversal process occur at relatively low external magnetic fields.

Studies of magnetization reversal processes were carried out on the $\operatorname{Pr}_{8} \mathrm{Dy}_{1} \mathrm{Fe}_{60} \mathrm{Co}_{7} \mathrm{Mn}_{6} \mathrm{~B}_{14} \mathrm{Zr}_{1} \mathrm{Ti}_{3}$ alloy sample revealing the best hard magnetic properties, based on measurement of recoil curves. From this measurements reversible magnetization curves (the dependences of reversible parts $M_{\text {rev }}$ on the irreversible parts $M_{\text {irr }}$ of magnetization for various external magnetic fields) were constructed. The shapes of $M_{\text {rev }}$ vs. $M_{\text {irr }}$ curves can give the information about the dominant magnetization reversal process that control the magnetic properties of the sample. For magnets where the nucleation process 
is dominant, reversed domains once nucleated, can expand and easily propagate through the grains. In this case $M_{\text {rev }}$ arises from rotation of the magnetization vectors and the $M_{\text {rev }}\left(M_{\text {irr }}\right)$ plots take the shapes of straight lines of negative slopes. For magnets where the dominant magnetization reversal process is the pinning of domain walls, the $M_{\text {rev }}\left(M_{\text {irr }}\right)$ curves show minimum, due to the fact that the reversible magnetization arises from the domain wall bowing [12]. Selected $M_{\text {rev }}$ vs. $M_{\text {irr }}$ curves for the $\operatorname{Pr}_{8} \mathrm{Dy}_{1} \mathrm{Fe}_{60} \mathrm{Co}_{7} \mathrm{Mn}_{6} \mathrm{~B}_{14} \mathrm{Zr}_{1} \mathrm{Ti}_{3}$ alloy $3 \mathrm{~mm}$ outer diameter tube are showed in Fig. 3. The reversible magnetization curves exhibit a shallow minimum for positive values of $M_{\mathrm{irr}}$, which moves toward of $M_{\mathrm{irr}}$ with the increase of the magnetic field. A shallow minimum on those curves suggests that for low magnetic fields the pinning of domains walls occurs, while for higher magnetic fields the nucleation process prevails. This is consistent with the shape of the initial magnetization curve (Fig. 2b) measured for the $\mathrm{Pr}_{8} \mathrm{Dy}_{1} \mathrm{Fe}_{60} \mathrm{Co}_{7} \mathrm{Mn}_{6} \mathrm{~B}_{14} \mathrm{Zr}_{1} \mathrm{Ti}_{3}$ alloy sample, where for the low magnetic relatively low values of magnetic polarization were measured, while for field higher than $800 \mathrm{kA} / \mathrm{m}$ a steeper increase of magnetic polarization was measured.

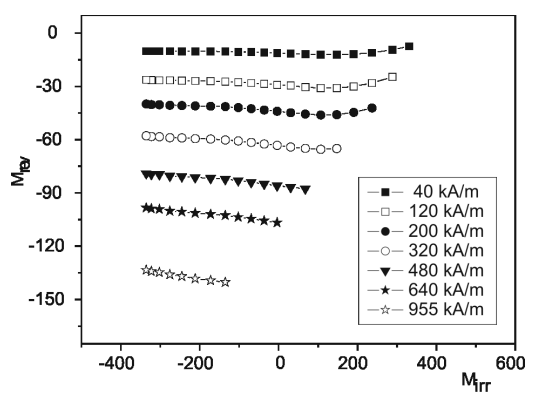

Fig. 3. Plots of reversible part of magnetization $M_{\text {rev }}$ as a function of irreversible magnetization $M_{\text {irr }}$ for the $\mathrm{Pr}_{8} \mathrm{Dy}_{1} \mathrm{Fe}_{60} \mathrm{Co}_{7} \mathrm{Mn}_{6} \mathrm{~B}_{14} \mathrm{Zr}_{1} \mathrm{Ti}_{3}$ alloy tubes.

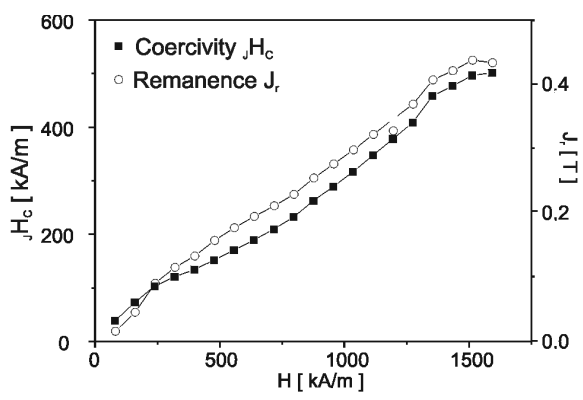

Fig. 4. Field dependences of coercivity ${ }_{J} H_{\mathrm{C}}$ and remanence $\mathrm{J}_{\mathrm{r}}$ for the $\mathrm{Pr}_{8} \mathrm{Dy}_{1} \mathrm{Fe}_{60} \mathrm{Co}_{7} \mathrm{Mn}_{6} \mathrm{~B}_{14} \mathrm{Zr}_{1} \mathrm{Ti}_{3}$ alloy tubes measured on initially demagnetized samples.

Additional information about the magnetization reversal process can provide the measurements of minor hysteresis loops for samples initially demagnetized. Investigation of minor hysteresis loops were carried out at room temperature using a vibrating sample magnetometer in the external magnetic field up to $1600 \mathrm{kA} / \mathrm{m}$. From those measurements the dependences of ${ }_{J} H_{\mathrm{c}}$ and $J_{\mathrm{r}}$ as the function the maximum external magnetic field $\mathrm{H}_{\max }$ were cal- culated and presented in Fig. 4. The characteristic almost straight line shapes of this dependences confirms the results obtained from the reversible magnetization curves. For the investigated alloy, magnetization reversal process is controlled both by the reversible movement of pinned domain walls (domain walls bowing) and the nucleation of reversed domains.

\section{Conclusions}

It was shown that all investigated $\mathrm{Pr}_{8} \mathrm{Dy}_{1} \mathrm{Fe}_{60} \mathrm{Co}_{7} \mathrm{Ni}_{(6-x)} \mathrm{Mn}_{x} \mathrm{~B}_{14} \mathrm{Zr}_{1} \mathrm{Ti}_{3}$ (where $x=0$, $3,6)$ alloys in the form of $3 \mathrm{~mm}$ outer diameter tubes are crystalline in as-cast state. For the $\mathrm{Pr}_{8} \mathrm{Dy}_{1} \mathrm{Fe}_{60} \mathrm{Co}_{7} \mathrm{Ni}_{6} \mathrm{~B}_{14} \mathrm{Zr}_{1} \mathrm{Ti}_{3}$ alloy the XRD analysis revealed multiphase constitution consisting of the hard magnetic $\operatorname{Pr}_{2}(\mathrm{Fe}, \mathrm{Co})_{14} \mathrm{~B}$ and soft magnetic $\alpha-(\mathrm{Fe}, \mathrm{Ni})$ phases. Replacement of $\mathrm{Ni}$ by $\mathrm{Mn}$ led to growth of the hard magnetic $\operatorname{Pr}_{2}(\mathrm{Fe}, \mathrm{Co})_{14} \mathrm{~B}$ phase and improvement of magnetic parameters. For specimens containing $\mathrm{Mn}$ the soft magnetic phase is not observed. The Rietveld analysis of the XRD scan for the $\operatorname{Pr}_{8} \mathrm{Dy}_{1} \mathrm{Fe}_{60} \mathrm{Co}_{7} \mathrm{Ni}_{6} \mathrm{~B}_{14} \mathrm{Zr}_{1} \mathrm{Ti}_{3}$ alloy has shown difference in the lattice constant of the $\alpha-(\mathrm{Fe}, \mathrm{Ni})$ phase $(a=0.287 \mathrm{~nm})$ comparing to the pure $\alpha$-Fe. In the Mn containing alloys the admixture elements are most likely located in the grain boundaries.

Studies of the magnetization reversal process for $\mathrm{Pr}_{8} \mathrm{Dy}_{1} \mathrm{Fe}_{60} \mathrm{Co}_{7} \mathrm{Mn}_{6} \mathrm{~B}_{14} \mathrm{Zr}_{1} \mathrm{Ti}_{3}$ alloy tubes shown that the mechanism of magnetization reversal is controlled by both: nucleation and pinning processes. The dependences of ${ }_{J} H_{\mathrm{c}}$ on the maximum external magnetic field demonstrate steady rise of its value with the increase of $H_{\text {max }}$. Also the shapes of the $M_{\text {rev }}$ vs. $M_{\text {irr }}$ suggest combined magnetization reversal process.

\section{References}

[1] J.J. Croat, J.F. Herbst, R.W. Lee, F.E. Pinkerton, J. Appl. Phys. 55, 2078 (1984).

[2] K. Suzuki, A. Makino, A. Inoue, T. Masumoto, J. Appl. Phys. 70, 6232 (1991).

[3] M.A. Willard, D.E. Laughlin, M.E. McHenry, D. Thoma, K. Sickafus, J.O. Cross, V.G. Harris, J. Appl. Phys. 84, 6773 (1998).

[4] P. Pawlik, H.A. Davies, J. Non-Cryst. Solids 329, 17 (2003).

[5] P. Pawlik, H.A. Davies, M.R.J. Gibbs, Mater. Sci. Eng. A 375-377, 372 (2004).

[6] A. Inoue, Bulk Amorphous Alloys, Trans Tech Publ., Zurich 1998, p. 1.

[7] P. Pawlik, M. Nabiałek, M. Żak, J. Zbroszczyk, J.J. Wysłocki, J. Olszewski, K. Pawlik, Archiv. Mater. Sci. 25, 177 (2004)(in Polish).

[8] P. Pawlik, H.A. Davies, M.R.J. Gibbs, Appl. Phys. Lett. 83, 2775 (2003).

[9] P. Pawlik, K. Pawlik, A. Przybył, Rev. Adv. Mater. Sci 18, 81 (2008).

[10] J.J. Wysłocki, P. Pawlik, JAMME 43, 463 (2010).

[11] A. Przybył, K. Pawlik, P. Pawlik, P. Gębara, J.J. Wysłocki, J. Alloys Comp. 536S, S333 (2012).

[12] D.C. Crew, L.H. Lewis, J. Appl. Phys. 87, 4783 (2000). 